mineral fibres. Lyons: International Agency for Research on Cancer, 1989:511-8. (IARC Scientific Publications No 90.)

22 Fraser G, Pare JAP, Pare PD, Fraser RS, Genereux GP. Diagnosis of diseases of the chest. Vol II 3rd ed. New York: Saunders, 1989.

23 Bridbord K, Decoufle P, Fraumeni JF Jr, Hoel DG, Hoover RN, Rall DP, et al. Estimates of the fraction of cancer in the United States relat DP, al. Estmated to occupational factors. In: Peto R, Schneiderman M, eds. Quantification of occupational cancer. New York:

24 Peto J, Henderson BE, Pike MC. Trends in mesothelioma incidence in the United States and the forecast epidemic due to asbestos exposure during WWII. In: Peto R, Schneiderman M, eds. Quantification of occupational cancer. New York: Cold Spring Harbor Laboratory, 1981:51-72. (Banbury report No 9.)

25 Enterline PE. Proportion of cancer due to exposure to asbestos. In: Peto R, Schneiderman M, eds. Quantification of occupational cancer. New York: Cold Spring Harbor Laboratory, 1981:19-36. (Banbury report No 9.)

26 Higginson J, Bahar JC, Clemmesen J, Demopoulos H, Garfinkel L, Hirayama T, et al. Proportion of cancers due to occupations. Prev Med 1980;9:180.

27 Parkes WR. Occupational lung disorders. 2nd ed. London: Butterworth, 1982.

28 Selikoff IJ, Churg J, Hammond EC. Asbestos exposure and neoplasia. \AMA 1964;188:22-6.
29 Martischnio KM, Newall DJ, Barnsley WC, Cowan WK, Feinmann EL Oliver $\mathrm{E}$. Unsuspected exposure to asbestos and bronchogenic carcinom BMF 1977; ; 746 .

30 Warnock ML, Isenberg W. Asbestos burden and the pathology of lung cancer Chest 1986;89:20.

31 Mancuso TF, Coulter EJ. Methodology in industrial health studies. Arch Environ Health 1963;6:210-26.

32 Sluis-Cremer GK. The relationship between asbestosis and bronchial cancer. Chest 1980;78 (suppl 2):380-1.

33 Roggli VL, Pratt PC, Brody AR. Asbestos content of lung tissue in asbestos associated diseases: a study of 110 cases. Br I Ind Med 1986;43:18-28.

34 Kipen HM, Lilis R, Suzuki Y, Valciukas JA, Selikoff IJ. Pulmonary fibrosis in asbestos insulation workers with lung cancer: a radiological and histopathological evaluation. Brf Ind Med 1987;44:96-100.

35 Hughes JM, Weill $\mathrm{H}$. Asbestosis as a precursor of asbestos-related lung cancer: results of a prospective mortality study. Br f Ind Med 1991;48:229-33.

36 Daniel FB. In vitro assessment of asbestos genotoxicity. Environ Health Perspect 1983;53:163-7.

37 Department of Social Security. Social security statistics 1989. London: HMSO, 1989.

(Accepted 8 April 1993)

\title{
A prospective study of alcohol consumption and bone mineral density
}

\author{
Troy L Holbrook, Elizabeth Barrett-Connor
}

\begin{abstract}
Objectives-To study the effects of alcohol consumption on bone mineral density in a defined population.
\end{abstract}

Design-Prospective study of bone mineral density, measured during 1988-91, in a cohort who had given baseline data on alcohol intake in the previous week and in the previous 24 hours and other factors affecting bone mineral density during 1973-5.

Setting-Rancho Bernardo, California.

Subjects -182 men and 267 women aged 45 and over at baseline, half having been randomly selected and half having been chosen for hyperlipidaemia, who gave baseline information on alcohol intake in one week. Of these subjects, 142 men and 220 women gave information on alcohol intake in 24 hours.

Main outcome measures-Bone mineral density of the radial shaft, ultradistal wrist, femoral neck, and lumbar spine.

Results-Men and women were considered separately, and the tertiles of alcohol consumption were used to delineate low, medium, and high values of alcohol intake. With increasing alcohol intake in one week, bone mineral density (adjusted for age, body mass index, smoking, taking exercise, and oestrogen replacement therapy in women) increased significantly in the femoral neck of men $(p<0.01)$ and the spine of women $(p<0.01)$. With increasing alcohol intake in 24 hours, adjusted bone mineral density increased significantly in the radial shaft $(p<0.05)$ and spine $(p<0.001)$ of women. Similar, but not significant, patterns were seen at the other bone sites.

Conclusions-Social drinking is associated with

Department of Community and Family Medicine, University of California, San Diego, La Jolla, CA 92093, USA

Troy L Holbrook, assistant adjunct professor Elizabeth Barrett-Connor, professor and chair

Correspondence to:

Professor Holbrook.

$B M \mp$ 1993;306:1506-9

\section{higher bone mineral density in men and women.}

\section{Introduction}

Osteoporosis is a leading cause of morbidity and disability among elderly populations in Western countries and is the most important underlying cause of fractures of the hip, spine, distal wrist, and humerus in elderly people. A higher body mass index is an established protective factor for osteoporosis, and recent evidence indicates that diet, smoking, exercise, and use of drugs may be important in the aetiology of this disease. ${ }^{1}$
Several studies have shown that alcohol consumption is also associated with osteoporosis and osteoporotic fractures, ${ }^{2-8}$ although most of these studies were on chronic alcoholics, who may have been seriously malnourished and more likely to fall. Alcohol is directly toxic to bone and may disrupt bone metabolism. ${ }^{10}$ Several recent reports, however, have suggested that alcohol consumption may be associated with higher bone mineral density in postmenopausal women, ${ }^{11-13}$ although others did not find this association. ${ }^{14}$ is All these reports were limited to women, and most were based on small numbers of volunteers, were cross-sectional, and did not control for other factors associated with bone mineral density. We describe a prospective study of the association of alcohol consumption with bone mineral density in a defined population of men and women.

\section{Subjects and methods}

During $1972-482 \%$ of all adult residents of a geographically defined, upper middle class, white community in Rancho Bernardo, California, participated in a survey of risk factors for heart disease. ${ }^{10}$ During 1973-5 30\% of this cohort were invited for a second, more extensive examination. Half of this group were randomly sampled from the original participants and the rest were all the hyperlipidaemic subjects from the original cohort (defined as those whose plasma cholesterol or triglyceride concentrations were at or above the age and sex specific 90th centiles for cholesterol or 95th centiles for triglycerides, or those who were taking lipid lowering drugs). Of those invited, $92 \%$ attended the clinic. The randomly selected and hyperlipidaemic subjects did not differ significantly with respect to diet or alcohol intake and were combined for this analysis, which used baseline data obtained during 1973-5.

The baseline data included information on cigarette smoking and drugs taken, including diuretics and oestrogen replacement therapy, obtained with standard questionnaires administered by interviewers; height and weight measured with the subjects in light clothing and without shoes; obesity estimated from the body mass index (weight $(\mathrm{kg}) /\left(\right.$ height $\left.(\mathrm{m})^{2}\right)$; and plasma aspartate aminotransferase activity determined by a modification of Karmen's method. ${ }^{17}$ Alcohol intake was based on two interviews: the reported average 
weekly consumption of all alcoholic drinks obtained by a trained interviewer, and the recall of all alcohol intake in the previous 24 hours obtained by a certified dietitian from a lipid research clinic with quantities assessed by use of containers and food models. Recall of calcium intake in the previous 24 hours was ascertained by the dietitian and coded with the 1985 database of the Nutrition Coordinating Center, University of Minnesota, for a subset of the cohort $(65 \%)$, whose other covariates had all been ascertained.

From 1988 older ambulatory members of the Rancho Bernardo cohort were invited to participate in a new study designed to study osteoporosis. Bone mineral density was measured in the non-dominant arm at the mid-shaft of the radius and ultradistal wrist with a single photon absorptiometry scanner (Lunar model SP2B, Madison, WI) and at the femoral neck and spine with a dual energy $x$ ray absorptiometry scanner (Hologic QDR model 1000, Waltham, MA). The bone mineral density of the spine was recorded as an average of the densities of the L1-L4 vertebrae. Men and women aged 45 or older when baseline data were collected and whose baseline and follow up data were complete were considered in this study. Their alcohol intake was reassessed about 12 years after the baseline measurement in the manner described previously.

The results for men and women were analysed separately, and the tertiles of alcohol consumption were used to delineate low, medium, and high values of alcohol intake. The distributions of covariates in relation to alcohol intake were compared by means of the $\chi^{2}$ test for discontinuous variables and analysis of variance for continuous variables. With non-drinkers categorised separately the independent contribution of alcohol intake to bone mineral density was estimated by analysis of covariance after adjusting for baseline age, body mass index, regular exercise, smoking, calcium intake in the previous 24 hours, and oestrogen replacement therapy in women. This analysis was valid because bone mineral density was found to be normally distributed at all the bone sites. Partial correlation coefficients of alcohol intake with serum aspartate aminotransferase, a marker of alcohol intake, were also examined.

\section{Results}

The results from 182 men and 267 women were used in the analysis of bone mineral density in relation to one week's alcohol intake, and the results from 142 men and 220 women were used in the analysis of bone density in relation to 24 hours' alcohol intake. Table I shows that the mean baseline distribution of age, body mass index, and taking regular exercise did not change with the previous week's alcohol intake in men. Men with a high alcohol intake $(>181.0 \mathrm{~g})$, however, were significantly more likely to be smokers than men who drank less. Women with a high alcohol intake $(>120.5 \mathrm{~g})$ had a significantly lower baseline age, body mass index, and were significantly more likely not to take regular exercise and to be smokers than women who drank less. There were no other significant differences in the baseline distribution of risk and protective factors in relation to alcohol intake. No men and few women took diuretics. In men and women the mean plasma aspartate aminotransferase concentration

TABLE I-Relation between factors associated with bone mineral density and alcohol intake in one week among 182 men and 267 women aged 45 or over

\begin{tabular}{|c|c|c|c|c|c|c|c|c|}
\hline & No & Age (years) & $\begin{array}{l}\text { Body mass } \\
\text { index }\left(\mathrm{kg} / \mathrm{m}^{2}\right)\end{array}$ & $\begin{array}{c}\text { Plasma aspartate } \\
\text { aminotransferase } \\
\text { concentration }(\mathrm{U} / \mathrm{l})\end{array}$ & $\begin{array}{c}\text { Calcium intake } \\
\text { in } 24 \text { hours (mg) }\end{array}$ & $\begin{array}{l}\text { No }(\%) \text { taking } \\
\text { regular exercise }\end{array}$ & No (\%) smoking & $\begin{array}{c}\text { No }(\%) \text { taking } \\
\text { oestrogen replacement } \\
\text { therapy }\end{array}$ \\
\hline \multicolumn{9}{|c|}{ Men } \\
\hline Mean (SD) & & $58 \cdot 8(8 \cdot 0)$ & $26 \cdot 2(3 \cdot 0)$ & $32.9(30 \cdot 5)$ & $856(506)$ & & & \\
\hline \multicolumn{9}{|l|}{ Alcohol intake (g): } \\
\hline None & 29 & $70 \cdot 0$ & $26 \cdot 5$ & $28 \cdot 0$ & 976 & $6(21)$ & $5(17)$ & \\
\hline Low $(0 \cdot 1-87 \cdot 3)$ & 51 & $59 \cdot 3$ & $26 \cdot 4$ & $27 \cdot 7$ & 850 & $10(20)$ & $6(12)$ & \\
\hline \multicolumn{9}{|l|}{ Medium } \\
\hline$(87 \cdot 4-180 \cdot 9)$ & 50 & $59 \cdot 7$ & $26 \cdot 0$ & $39 \cdot 6$ & 827 & $8(16)$ & $5(10)$ & \\
\hline $\operatorname{High}(\geqslant 181 \cdot 0)$ & 52 & $56 \cdot 8$ & $25 \cdot 9$ & $34 \cdot 3$ & 831 & $7(13)$ & $15(29) \star \star$ & \\
\hline \multicolumn{9}{|c|}{ Women } \\
\hline Mean (SD) & & $59 \cdot 8(7 \cdot 8)$ & $24 \cdot 1(3 \cdot 4)$ & $25 \cdot 5(10 \cdot 4)$ & $646(364)$ & & & \\
\hline \multicolumn{9}{|c|}{ Alcohol intake $(\mathrm{g}): \ddagger$} \\
\hline None & 71 & $61 \cdot 1$ & $25 \cdot 3$ & $23 \cdot 9$ & 686 & $3(4)$ & $10(14)$ & $22(31)$ \\
\hline $\operatorname{Low}(0 \cdot 1-48 \cdot 6)$ & 66 & $60 \cdot 5$ & $24 \cdot 1$ & $24 \cdot 5$ & 652 & $11(17)$ & $10(15)$ & $20(30)$ \\
\hline \multicolumn{9}{|l|}{ Medium } \\
\hline$(48 \cdot 7-120 \cdot 4)$ & 63 & $60 \cdot 6$ & $23 \cdot 8$ & $25 \cdot 0$ & 679 & $4(6)$ & $13(21)$ & $17(27)$ \\
\hline High $(\geqslant 120 \cdot 5)$ & 67 & $57 \cdot 6^{\star}$ & $22 \cdot 9^{\star \star \star}$ & $28 \cdot 7^{\star}$ & 587 & $3(4)^{\star}$ & $30(45)^{\star \star \star}$ & $22(33)$ \\
\hline
\end{tabular}

${ }^{\star} \mathrm{p}<0 \cdot 05,{ }^{\star \star} \mathrm{p}<0 \cdot 01,{ }^{\star \star \star} \mathrm{p}<0 \cdot 001$

†Mean (SD) alcohol intake $=46 \cdot 2(24 \cdot 7) \mathrm{g}$ for low intake, $136 \cdot 3(26 \cdot 9) \mathrm{g}$ for medium intake, $324 \cdot 3(115 \cdot 5) \mathrm{g}$ for high intake.

$\ddagger$ Mean (SD) alcohol intake $=23 \cdot 8(12 \cdot 0) \mathrm{g}$ for low intake, $84 \cdot 3(18 \cdot 7) \mathrm{g}$ for medium intake, $224 \cdot 6(73 \cdot 5) \mathrm{g}$ for high intake.

TABLE II-Relation between factors associated with bone mineral density and alcohol intake in 24 hours among 142 men and 220 women aged 45 or over

\begin{tabular}{|c|c|c|c|c|c|c|c|c|}
\hline & No & Age (years) & $\begin{array}{c}\text { Body mass } \\
\text { index }\left(\mathrm{kg} / \mathrm{m}^{2}\right)\end{array}$ & $\begin{array}{l}\text { Plasma aspartate } \\
\text { aminotransferase } \\
\text { concentration (U/l) }\end{array}$ & $\begin{array}{l}\text { Calcium intake } \\
\text { in } 24 \text { hours (mg) }\end{array}$ & $\begin{array}{l}\text { No }(\%) \text { taking } \\
\text { regular exercise }\end{array}$ & No (\%) smoking & $\begin{array}{c}\text { No }(\%) \text { taking } \\
\text { oestrogen replacement } \\
\text { therapy }\end{array}$ \\
\hline \multicolumn{9}{|c|}{ Men } \\
\hline Mean (SD) & & $59 \cdot 0(7 \cdot 6)$ & $26 \cdot 4(3 \cdot 1)$ & $33 \cdot 7(38 \cdot 5)$ & $856(505)$ & & & \\
\hline \multicolumn{9}{|c|}{ Alcohol intake $(\mathrm{g}): \dagger$} \\
\hline None & 54 & $59 \cdot 3$ & $26 \cdot 9$ & $26 \cdot 1$ & 962 & $12(22)$ & $8(15)$ & \\
\hline $\operatorname{Low}(0 \cdot 1-19 \cdot 1)$ & 27 & $59 \cdot 4$ & $26 \cdot 6$ & $29 \cdot 1$ & 898 & $4(15)$ & $5(19)$ & \\
\hline \multicolumn{9}{|l|}{ Medium } \\
\hline$(19 \cdot 2-41 \cdot 1)$ & 31 & $60 \cdot 1$ & $25 \cdot 4$ & $43 \cdot 3$ & 793 & $7(23)$ & $2(6)$ & \\
\hline High $(\geqslant 41 \cdot 2)$ & 30 & $58 \cdot 0$ & $26 \cdot 4$ & $40 \cdot 8$ & 702 & $7(23)$ & $7(23)^{\star \star}$ & \\
\hline \multicolumn{9}{|c|}{ Women } \\
\hline Mean $(S D)$ & & $60 \cdot 3(7 \cdot 5)$ & $24 \cdot 1(3 \cdot 5)$ & $25 \cdot 0(10 \cdot 2)$ & $856(505)$ & & & \\
\hline \multicolumn{9}{|c|}{ Alcohol intake $(\mathrm{g}): \ddagger$} \\
\hline None & 116 & $60 \cdot 7$ & $24 \cdot 3$ & $25 \cdot 3$ & 674 & $10(9)$ & $19(16)$ & $41(35)$ \\
\hline Low $(0 \cdot 1-14 \cdot 3)$ & 25 & $60 \cdot 8$ & $24 \cdot 6$ & $24 \cdot 8$ & 569 & $2(8)$ & $6(24)$ & $9(36)$ \\
\hline \multicolumn{9}{|l|}{ Medium } \\
\hline$(14 \cdot 4-28 \cdot 8)$ & 30 & 61.5 & 23.5 & $24 \cdot 2$ & 779 & $1(3)$ & $9(30)$ & $9(30)$ \\
\hline High $(\geqslant 128.9)$ & 49 & $58 \cdot 4$ & $23 \cdot 7$ & $25 \cdot 0$ & $559^{\star}$ & $5(10)$ & $17(35)^{\star}$ & $16(33)$ \\
\hline
\end{tabular}

${ }^{\star} \mathrm{p}<0.05,{ }^{\star \star} \mathrm{p}<0.01$.

† Mean (SD) alcohol intake $=14 \cdot 2(3 \cdot 0) \mathrm{g}$ for low intake, $28 \cdot 6(5 \cdot 8) \mathrm{g}$ for medium intake, $63 \cdot 2(21 \cdot 4) \mathrm{g}$ for high intake.

$\ddagger$ Mean (SD) alcohol intake $=8 \cdot 5(3 \cdot 7) \mathrm{g}$ for low intake, $18 \cdot 5(4 \cdot 1) \mathrm{g}$ for medium intake, $41 \cdot 7(15 \cdot 7) \mathrm{g}$ for high intake. 

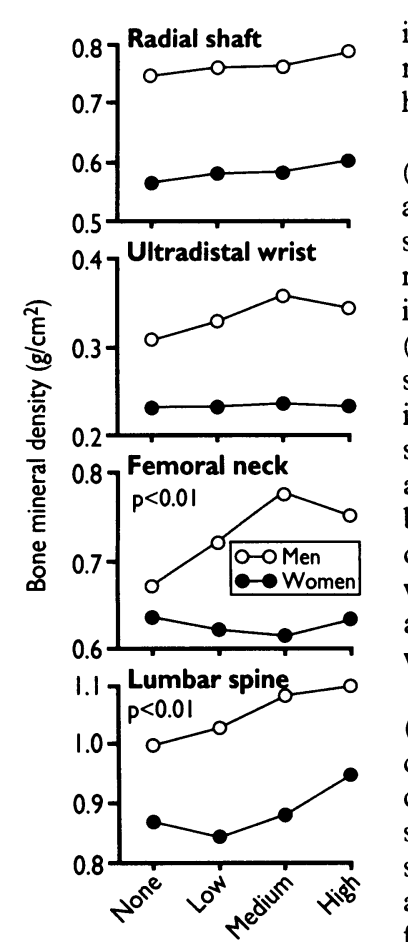

Alcohol intake in one week

Adjusted mean bone mineral density of four sites in relation to alcohol intake in one week. (Low alcohol intake $=0 \cdot 1-87 \cdot 3 \mathrm{~g}$ for men, $0 \cdot 1-48 \cdot 6 \mathrm{~g}$ for women; medium intake $=87.4-180 \cdot 9 \mathrm{~g}$ for men, $48 \cdot 7-120 \cdot 4 \mathrm{~g}$ for women; high intake $=\geqslant 181.0 \mathrm{~g}$ for men, $\geqslant 120 \cdot 5$ gfor women)

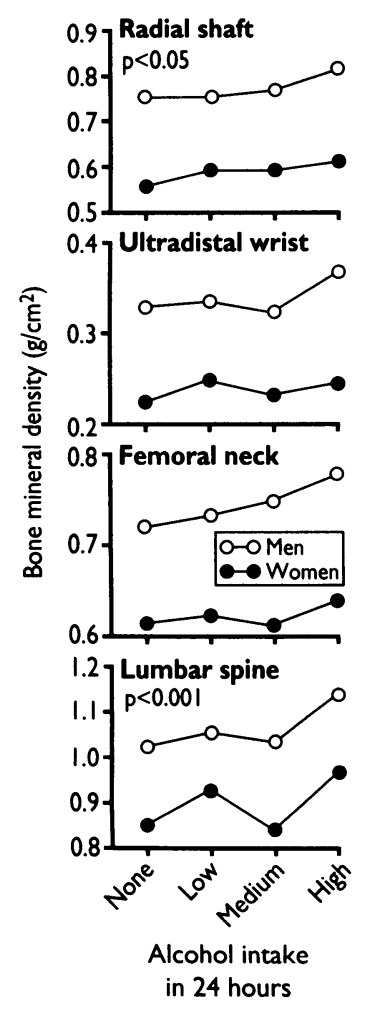

Adjusted mean bone mineral density of four sites in relation to alcohol intake in 24 hours. (Low alcohol intake $=0 \cdot 1-19 \cdot 1 \mathrm{~g}$ for men, 0.1-14.3 g for women; medium intake $=19 \cdot 2-41 \cdot 1 \mathrm{~g}$ for men, $14 \cdot 4-28 \cdot 8 \mathrm{~g}$ for women; high intake $=\geqslant 41 \cdot 2 \mathrm{~g}$ for men, $\geqslant 28.9 \mathrm{~g}$ for women increased with increasing reported alcohol intake. The results with alcohol intake during the previous 24 hours were generally similar (table II).

Figure 1 shows the mean bone mineral density (adjusted for age, body mass index, exercise, smoking and oestrogen replacement therapy in women) for each site in relation to one week's alcohol intake. In men the mean bone mineral density of the femoral neck increased significantly with increasing alcohol intake $(p<0.01)$, and in women bone mineral density in the spine increased significantly with increasing alcohol intake $(p<0.01)$. In men and women similar, but not significant, changes in bone mineral density were seen at other sites, changes in density of the spine in men being marginally significant $(p=0 \cdot 06)$. Bone mineral density in the femoral neck and spine of men and women was also positively correlated with plasma aspartate aminotransferase concentration $(p<0.05$ in women).

Results were similar with alcohol intake in 24 hours (fig 2). In women the adjusted mean bone mineral density in the radial shaft and spine increased significantly with increasing alcohol intake. In the smaller sample of men similar changes in bone density were seen but were not significant. The relation between alcohol intake and bone mineral density remained after further adjustment for calcium intake in 24 hours.

In women there was no significant association between the amount of alcohol consumed and the length of use of oestrogen replacement therapy, a major determinant of bone mineral density. The average time of receiving oestrogen replacement therapy was 10.4 years. When alcohol intake was reassessed about 12 years after the baseline measurement, more than $75 \%$ of men and women who had had high alcohol intake at baseline were still in the top third of alcohol consumers, and more than $60 \%$ of nondrinkers at baseline were still non-drinkers. Examination of the association between the later alcohol intake and bone mineral density revealed similar patterns to those seen before for each bone site in men and women. For example, the adjusted mean bone mineral density of the spine in men with no, low, medium, and high alcohol intake in one week was 1.055, 1.033, 1.044, and $1.074 \mathrm{~g} / \mathrm{cm}^{2}$ respectively $(\mathrm{p}=0.74)$; and in women the bone mineral density was $0.865,0.865,0.900$, and $0.951 \mathrm{~g} / \mathrm{cm}^{2}$ respectively $(\mathrm{p}<0.05)$.

\section{Discussion}

In this prospective study bone mineral density in men and women tended to increase with increasing alcohol intake, which had been reported 16-18 years earlier. The association was independent of baseline age, body mass index, smoking, taking regular exercise, and women taking oestrogen replacement therapy. Indeed, women with medium to high baseline measurements of alcohol intake were more likely to have been smokers, thinner, and to have exercised less, all factors associated with lower bone mineral density not with the observed results. In addition there was no relation between the duration of women taking oestrogen replacement therapy and their baseline alcohol intake.

These findings were based on separate assessments of alcohol intake by two trained interviewers, and the two sets of results were consistent in men and women. Although alcohol intake was self reported, many members of this study reported substantial social drinking as normal behaviour. Reported alcohol intake was validated indirectly by its positive and significant correlation with plasma aspartate aminotransferase and high density lipoprotein cholesterol concentrations. ${ }^{19}$ The association of alcohol intake with bone mineral density was also supported by the positive correlation between plasma aspartate aminotransferase activity and bone mineral density in the femoral neck and spine. The magnitude of the association was possibly underestimated since errors of measurement in observational studies tend to reduce or obscure a true association. ${ }^{20}$

One limitation of prospective epidemiological studies is that the distribution of risk factors and covariates may change during the follow up, and such changes could alter the observed associations. We, however, found that most of our subjects had not substantially changed alcohol intake 12 years after the baseline measurements. Furthermore, when we reassessed the association between alcohol intake and bone mineral density with the more recent data on alcohol intake the patterns remained almost identical at each bone site.

Epidemiological evidence for an association between social drinking and bone mineral density is limited. Hansen et al observed a decreased rate of bone loss in 121 postmenopausal women with moderate alcohol consumption followed prospectively over a 12 year period..$^{13}$ In a cross-sectional study of women Laitinen et al reported higher bone mineral density in postmenopausal women who drank alcohol." Similar observations were made by Angus et al. ${ }^{12}$ None of these studies included adjustment for the effects of potentially important confounding variables such as obesity, taking exercise, smoking, and dietary calcium intake.

In contrast to these findings, several studies have reported an increased risk of osteoporotic fractures with alcohol intake. ${ }^{2-6}$ Studies of fractures and alcohol consumption, however, are confounded by other risk factors for fracture, including malnutrition, smoking, increased likelihood of falling, impaired vision, and neuromuscular dysfunction. Although alcohol has been shown to have direct toxic effects on bone and to disrupt bone metabolism, ${ }^{910}$ these observations have been largely based on studies of chronic alcoholics, and it is not clear if the effects of alcohol on bone mineral density are independent of the associated metabolic and nutritional consequences of chronic alcohol misuse. Indeed, several cross-sectional studies have failed to demonstrate lower bone mineral density in alcoholics, but these studies were based largely on middle aged men with little data for women. ${ }^{21-24}$

The biological mechanism by which increased alcohol intake could promote higher bone mineral density is unclear. Laitinen proposed that it might be due to the effect of alcohol intake on endogenous hormone levels. ${ }^{10}$ In one study of European women alcohol intake was positively correlated with serum oestradiol concentration. ${ }^{25}$ Further evidence comes from the observation that alcohol intake induces the adrenal production of androstenedione and its extraadrenal conversion to oestrone. How such conversions would operate in men, in whom the association of endogenous oestrogens with bone mineral density is not established, remains unclear.

This study suggests that moderate social drinking is associated with higher bone mineral density in both men and women. Although alcohol consumption cannot be recommended as a preventative for osteoporosis, it is reassuring that social drinking appears to have no negative effect on bone density. Further studies are needed to determine how alcohol intake affects bone mineral density.

This work was funded by grant AG 07181 from the National Institute of Aging.

\footnotetext{
1 Law MR, Wald NJ, Meade TW. Strategies for prevention of osteoporosis and

hip fracture. $B M 71991 ; 303: 453-9$.
. roentgen in alcoholics. Acta Orshop Scand 1980;51:205-7.

3 Israel Y, Orrego H, Holt S, Macdonald DW, Meema HE. Identification of alcohol abuse: thoracic fractures on routine $\mathrm{X}$-rays as indicators of alcoholism. Alcoholism 1980;4:420-2.
} 
4 Johnson RD, Davidson S, Saunders JB, Williams R. Fractures on chest radiography as indicators of alcoholism in patients with liver disease. $B M$ 1984;288:365-6.

5 Johnell $\mathrm{O}$, Kristenson $\mathrm{H}$, Redlund-Johnell I. Lower limb fractures and registration for alcoholism. Scand 7 Soc Med 1985;13:95-7.

6 Cooper C, Parker DJP, Morris J, Briggs RS. Osteoporosis, falls, and age in fracture of the proximal femur. $B M \mathcal{H}$ 1987;295:13-5.

7 Seeman E, Melton LJ 3rd, O'Fallon WM, Riggs BL. Risk factors for spinal osteoporosis in men. Am F Med 1983;75:977-83.

8 Saville PD. Changes in bone mass with age and alcoholism. $f$ Bone foint Surg $[\mathrm{Am}]$ 1965;47:492-9.

9 Rico H. Alcohol and bone disease. Alcohol Alcohol 1990;25:345-52.

10 Laitinen K, Valimaki M. Alcohol and bone. Calcif Tissue Int 1991;49(suppl): S70-3.

1 Laitinen $\mathrm{K}$, Valimaki $\mathrm{M}$, Keto $\mathrm{P}$. Bone mineral density measured by dualenergy X-ray absorptiometry in healthy Finnish women. Calcif Tissue Int (in press).

12 Angus RM, Sambrook PN, Pocock NA. Dietary intake and bone mineral density. Bone Miner 1988;4:265-77.

13 Hansen MA, Overgaard K, Riis BJ, Christiansen C. Potential risk factors for development of postmenopausal osteoporosis examined over a 12-year development of postmenopausal osteoporosis

14 Stevenson JC, Lees B, Devenport M, Cust MP, Ganger KF. Determinants of bone density in normal women: risk factors for future osteoporosis? $B M$ 1989;298:924-8.

15 Hall ML, Heavens J, Cullum ID, Ell PJ. The range of bone density in normal British women. Br $\mathcal{Y}$ Radiol 1990;63:266-9.

16 Criqui MH, Barrett-Connor E, Austin M. Differences between respondents and non-respondents in a population-based cardiovascular disease study. Am J Epidemiol 1978;108:367-72.
17 Henry RJ, Chiamori N, Golub OJ, Berkman S. Revised spectrophotometric methods for the determination of glutamic-oxalacetic transaminase and lactic dehydrogenase. Am f Clin Pathol 1960;34:381-98.

18 Jones BR, Barrett-Connor E, Criqui MH, Holdbrook MJ. A community study of calorie and nutrient intake in drinkers and nondrinkers of alcohol. $\mathrm{Am} \mathcal{f}$ Clin Nutr 1982;35:135-9.

19 Barrett-Connor E, Suarez L. A community study of alcohol and other factors associated with the distribution of high density lipoprotein cholesterol in older vs. younger men. $A m \mathcal{F}$ Epidemiol 1982;115:888-93.

20 Greenland $\mathrm{S}$. The effect of misclassification in the presence of covariates. $\mathrm{Am}$ Epidemiol 1980;112:564-9.

21 Bjorneboe G-EA, Bjorneboe A, Johnsen J, Skylv N, Oftebro H, Gautvik KM et al. Calcium status and calcium-regulating hormones in alcoholics. Alcoholism 1988;12:229-32.

22 Laitinen K, Valimaki M, Lamberg-Allardt C, Kivisaari L, Lalla M, Karkkainen $\mathrm{M}$, et al. Deranged vitamin D metabolism but normal bone mineral density in Finnish noncirrhotic male alcoholics. Alcoholism 1990;14: 551-6.

23 Johnell $O$, Nilsson BE. Bone mineral content in men with fractures of the upper end of the femur. Int Orhop 1984;7:229-31.

24 Harding A, Dunlap J, Cook S, Mattalino A, Azar F, O'Brien M, et al Osteoporotic correlates of alcoholism in young males. Orthopedics 1988;11: 279-82.

25 Gavaler JS, Love K, Ortega CT. An international study of the relationship between alcohol consumption and postmenopausal estradiol. In: Khalant $\mathrm{H}_{3}$ Khanna JM, Israel Y, eds. Advances in biomedical alcohol research: proceedings of the 5th ISBRA/RSA congress. Oxford: Pergamon Press, 1991:327-30.

(Accepted 23 March 1993)

\title{
Risk assessment adjusted for gestational age in maternal serum screening for Down's syndrome
}

\author{
Jason Gardosi, Max Mongelli
}

\section{Abstract}

Objective-To investigate the relation between errors in calculation of gestational age and assessment of risk of Down's syndrome and to analyse the implications for screening programmes.

Design-Retrospective analysis of dating of gestational age by menstrual history $v$ ultrasound scan. Computer program with maternal age and concentrations of $\alpha$ fetoprotein and free $B$ human chorionic gonadotrophin to calculate risk for a range of expected dates of delivery. Computer simulated prospective application of new screening programme.

Setting-Teaching hospitals in Nottingham.

Subjects-31561 women with singleton pregnancies with gestational age based on routine ultrasound scan. Computer simulation of 20000 women in three age ranges (up to 37 ; up to 40 ; all).

Main outcome measures-Distribution of error between gestational age based on ultrasound scan $v$ menstrual history. Proportion of women in the population who require precise dating of pregnancy; proportion of women who require amniocentesis.

Results-With gestational age derived from ultrasound scan as reference the $95 \%$ confidence interval for gestational age by menstrual history was -27 to +9 days. A screening programme for Down's syndrome for women up to age $\mathbf{4 0}$ would yield a low risk $(<1: 250)$ for this range of days in $86.0 \%$ of cases. The $14.0 \%$ of women remaining would have one or more high risk values in their report and would thus require an ultrasound scan for precise dating of the pregnancy; $30 \%$ of these-that is, $3.7 \%$ of the screened population-would be identified as high risk and require consideration for amniocentesis.

Conclusions-Screening programmes for Down's syndrome require the facility for precise dating of pregnancy to improve the accuracy of risk assessment. This can be achieved without introducing additional scans for early dating in the whole population but by selecting only those cases (about $14 \%$ ) when an error in dates is likely to affect the risk of Down's syndrome.

\section{Introduction}

Biochemical screening to determine the risk of Down's syndrome in all pregnancies has been advocated ${ }^{\prime}$ and is being introduced in most health districts in the United Kingdom. ${ }^{2}$ Normal values for the biochemical analytes such as human chorionic gonadotrophin and $\alpha$ fetoprotein vary considerably with gestational age, and correct dates are required to make the result accurate. ${ }^{3} \mathrm{~A}$ recent attempt to establish population screening in Nottingham, relying on dating by mentrual history, was soon abandoned because of confusion caused by false positive test results from wrong dates, which led to a threefold rise in referrals for amniocentesis during the last quarter of 1991.

Most maternity units check the menstrual dates at the time of a routine scan for structural anomaly of the fetus at 18-19 weeks' gestation. The recommended time for the serum test for Down's syndrome is earlier, at about 16 weeks, which also allows the simultaneous assessment of $\alpha$ fetoprotein as an additional screen for neural tube defects. This means that the pregnancy dates have often not been checked by ultrasonography by the time the risk of Down's syndrome is reported, and it has therefore been suggested that an earlier scan is required to date all pregnancies for purposes of screening. ' This would have considerable logistical and financial implications, quite apart from the cost of the serum test itself. We investigated how the method of risk assessment could be improved without having to resort to routine, early scan dating of all pregnant women.

\section{Subjects and methods}

To examine the relation between the risk of Down's syndrome and gestational age a computer program was written (Turbo Pascal, Borland International, California) to calculate risk over a range of days before and after a given gestational age derived from the date of the last menstrual period at the time of the blood sample. Coefficients for the variables considered relevant in a particular population can be entered. In this program we multiplied the risk related to maternal 